\title{
Caracterización de la Edad del Bronce en La Mancha. Algunas proposiciones para su estudio
}

\author{
Manuel Fernández-Miranda \\ $M{ }^{a}$ DOLORES FERNANDEZ-POSSE \\ CONCEPCIÓN MARTIN *
}

La caracterización de los distintos grupos arqueológicos que concretan la imagen cultural que, por convención tan admitida como discutible, se denomina "Edad del Bronce" en la Península Ibérica es una de las cuestiones que la prehistoria española tiene aún pendiente de explicación. Aceptado el sentido de la referencia «Edad del Bronce» en su globalidad -excepción hecha de ciertas periodizaciones de corte instrumentalista formuladas allá por los años cincuenta - hace tiempo se comprobó que, al margen de su operativo valor convencional, resultaba imposible asignar a tal concepto un significado cultural uniforme, tampoco tipológico y tal vez ni siquiera tecnológico.

Los primeros intentos de sistematización, partiendo de modelos estipulados para la prehistoria europea, fueron realizados por Bosch Gimpera en los años treinta y cuarenta (un resumen de esa labor puede verse en su trabajo "La edad del bronce en la Península Ibérica", AEArq. 1954). La peculiaridad de los grupos arqueológicos peninsulares, así como su heterogeneidad, hacian no obstante muy dificil llevar adelante tal empeño, y las posibilidades de establecer paralelismos para adecuar el registro arqueológico aquí detectado a las secuencias propuestas para la Europa Central o Francia eran ciertamente escasas. Pese a ello, aunque con algunas rectificaciones, Bosch Gimpera no dudó en trasiadar el esquema europeo, si bien la mayoría de las ventajas que en principio supone la adopción de un sistema de periodización convencional, quedaban

* Universidad Complutense, Madrid. 
en buena parte anuladas por las dificultades surgidas a la ahora de comparar secuencias y objetos.

En el citado artículo de 1954 Bosch Gimpera modificó sustancialmente sus anteriores puntos de vista, tanto en lo que se referia al modelo general de periodización propuesto, más complejo que los anteriores y distanciado ya claramente de los prototipos europeos en que previamente se había apoyado, como en lo tratante a la aceptación de la diversidad regional de la península, si bien es cierto que su documentación primordial seguía basada en los datos procedentes del sureste, donde la información disponible era particularmente relevante gracias a los trabajos de excavación y exploración que Luis Siret había realizado hasta los años treinta.

El nuevo esquema de Bosch Gimpera se beneficiaba de dos fuentes teóricas de distinta entidad. Por un lado, en la mejor tradición arqueográfica germánica, divide y subdivide sus períodos iniciales creando una multiplicidad de fases fundamentada en la supuesta existencia de distintos estilos cerámicos campaniformes con valor cronológico, para el caso del Calcolítico, o en la discutible comprobación de cambios, también con el mismo valor, en los conjuntos de ajuares de los poblados argáricos, para el caso de la edad del Bronce. Esa creciente complejidad, consecuencia de una evidente tergiversación de los principios convencionales en que habia basado sus primeros intentos periodizadores, ya no le abandonará nunca. La segunda influencia tiene más interés en relación con el objeto de estas líneas, y se refiere a la nueva visión fragmentada de la edad del Bronce peninsular frente a la anterior concepción unitaria 0 , cuando menos, de tendencia marcadamente homogeneizadora.

Como es bien conocido, fue Tarradell $(1947,1949)$ el primer investigador que planteó la existencia de áreas diversas para la edad del Bronce peninsular al revisar el propio concepto de la llamada cultura argárica y su marco territorial. Hasta sus trabajos la simple presencia de objetos aislados con tipos próximos a los exhumados por Siret en El Argar bastaba para hablar de expansión de la cultura en cuestión hasta tierras bien alejadas del sureste peninsular. La argumentación servía, a su vez, para ofrecer una visión uniforme de toda la península a partir de una cultura bien definida en su "foco" originario, que después conservaba sus principales características a través de un amplio espacio, aunque perdiendo algunos de sus signos de identidad, en la medida en que toda difusión a partir de cualquier zona álgida diluye tales señales. Ocurría así que, al final, meras similitudes formales de carácter individual servian para establecer paralelismos más o menos felices. Pero una cultura, como escribiera Tarradell en el segundo de los artículos citados, 
«es algo excesivamente complejo para que pueda identificarse por el simple perfil de un vaso o por un solo tipo de arma, elementos que, aislados, pocas veces tienen valor definitivo".

En su artículo de 1949 Tarradell propone tres zonas culturales para la época argárica:

- zona de cultura argárica propiamente dicha, localizada en el sureste de España,

- zona de influencia argárica, que abarca Andalucía, Albacete, Valencia y posiblemente Mallorca y sur de Portugal,

- zona de perduración del Bronce I, para el resto de la península.

Dentro de la zona de influencia argárica, Tarradell notaba, a su vez, la existencia de grupos dispares. La «influencia argárica" la definía por la «existencia de la vida semiurbana, en poblados generalmente más rudimentarios que los argáricos", asi como por la presencia de tipos cerámicos y metálicos emparentables con los que igualmente se documentan en ambiente argárico. Pero esa zona de ascendencia, lejos de ser un área de igual naturaleza, sugería por el contrario distintos modos de vida, de acuerdo con el registro arqueológico. Asi surgía la identificación de varias unidades culturales, la valenciana, la de Albacete, la andaluza occidental o la más dudosa de Mallorca. En concreto para el caso de Albacete se singularizaba una unidad cultural específica caracterizada por encontrarse en una zona "directamente influida por lo argárico". El modelo alternativo de Tarradell tenía carácter provisional, como el propio autor señalaba en su artículo, pero servía para desechar, también en sus palabras, "la idea de una peninsula unificada por la cultura argárica».

La visión regionalizada fue aceptada y traspasada a sus esquemas por Bosch Gimpera (1954), que asignó sin dudar la denominación “Cultura de El Argar" para la misma zona que Tarradell consideraba nuclear, aunque se resistiera a la renuncia a hablar de elementos argáricos en puntos bien alejados de aquella, como Cataluña, Asturias... Bosch, en realidad, utiliza sólo en parte el esquema "cultural" de Tarradell y, tal vez como consecuencia de su tendencia a formular compendios para amplios territorios basados en la presencia de elementos aislados paralelizables, no deja de ver influjos expansivos argáricos por toda la península ibérica. En el fondo eran dos maneras distintas de tratar el mismo problema desde un enfoque difusionista, atenuado ligeramente en el primer caso por la atinada observación de la fragmentación regional, que a Bosch le costaba trabajo aceptar. 
La identificación científica de una unidad cultural singular en La Mancha durante la edad del Bronce no se logró hasta estos últimos años, si bien, y aunque el avance experimentado haya sido notable gracias al desarrollo simultáneo de distintos proyectos de investigación, todavía quedan muchos asuntos pendientes de dilucidar, tanto en lo que se refiere a su definición global como a sus posibles rasgos de variabilidad, límites cronológicos y geográficos... Esta singularización arranca precisamente de la especificación, sugerida años atrás por Tarradell, de un ambiente de influencia argárica en la actual provincia de Albacete que, en la concepción que entonces se empezaba a vislumbrar a propósito de la diversidad cultural peninsular para la edad del Bronce, aparecia como una prolongación de la cultura de El Argar, aunque con cierta personalidad propia y fuera del considerado espacio nuclear argárico.

La delimitación de ese espacio cultural ha constituido repetido objeto de debate desde la propuesta de Tarradell. Recientemente Lull la ha intentado de nuevo, con todas las dificultades que un trabajo de ese tipo conlleva, ante la falta de excavaciones sistemáticas en muchos de los territorios frontera y los apriorismos con que frecuentemente se ha clasificado determinados yacimientos, en un desmedido afán por mostrar como argárico lo que evidentemente no lo es en bastantes casos (Lull, 1983). A nosotros nos interesa aquí tratar el problema de los límites septentrionales de la llamada cultura de El Argar. Hacia el País valenciano opina Lull que la frontera debe colocarse en el valle del río Segura, y no llevarla hasta el Vinalopó, como otros autores han sugerido. Ese deslinde deja al norte yacimientos que, en todo caso, habría que catalogar como de transición entre Argar y Bronce valenciano, sobre todo hacia las tierras altas, en el eje Jumilla-Yecla-Villena, yacimientos que a su vez ocupan una franja intermedia precisamente entre las dos unidades culturales citadas y el Bronce de La Mancha. El límite por el río Segura habia sido ya propuesto por Tarradell en 1949. Ese río parece marcar, por otro lado, el confín en dirección oeste, de manera que al norte de él ya no habría poblados propiamente argáricos, hasta entroncar con las estribaciones montañosas más orientales de la Sierra del Segura, que constituirian igualmente otra clara barrera por ese extremo.

Con una visión tan precisa de la frontera septentrional de la cultura argárica no debe sorprender que al norte de la linde aparezcan, prácticamente sin discontinuidad alguna, los primeros asentamientos emparentables con el grupo de Albacete o, mejor aún, manchego. En efecto, la línea Hellín-Albatana-Montealegre del Castillo-Almansa está ocupada por poblados de distinta tipología -morras en unos casos y cerros aislados en otros- que proporcionan en prospección registros arqueológicos vin- 
culados a los que más al norte caracterizan a los asentamientos de la edad del Bronce. Aunque el conocimiento de esa zona sureste de la provincia de Albacete es todavía leve, tal vez con excepción del término de Almansa (Simón, 1987), los resultados de exploraciones y las noticias de algunas excavaciones parciales parecen no provocar excesivas dudas respecto a las diferencias existentes entre estos yacimientos del borde suroriental de la meseta y los del valle del Segura.

Una posibilidad para valorar las "influencias" argáricas sobre el sureste de La Mancha podria basarse en el análisis riguroso de ese espacio, que curiosamente coincide bastante bien con el actual límite administrativo entre Murcia y Alicante con Albacete, concebido como área de transición. Ocurre, sin embargo, que el territorio entre Jumilla, Yecla y Villena resulta ser uno de los más discutidos a la hora de adscribir los hallazgos de la edad del Bronce a unidades culturales concretas, quizá precisamente por el carácter transitivo de toda esa región, por otra parte sin excesivos obstáculos naturales que dificulten el contacto a su través.

La zona de frontera entre el área argárica estrictamente considerada y la que corresponde al Bronce de La Mancha en lo que se refiere al sureste de la provincia de Albacete quedaría por tanto relativamente clara, y lo mismo respecto del Bronce valenciano, siempre que se acepte que el valle del Vinalopó pertenece ya a ese otro espacio cultural. Sin embargo la imprecisión con que habitualmente se clasifican los yacimientos de esas tierras, tanto entre el Segura y el Vinalopó como desde las zonas bajas hasta las altas, podría constituir buen indicio de la existencia de un característico espacio intermedio en el que entran en contacto tres unidades culturales bastante bien definidas en sus áreas centrales respectivas pero mucho mejor lógicamente en sus bordes, donde las interrelaciones y los préstamos intrincan la filiación arqueológica exacta de yacimientos singulares e incluso de determinadas comarcas consideradas globalmente.

Hacia el interior de la Meseta sur y hasta el valle del Tajo al norte y la serranía de Cuenca o el límite occidental de las llanadas de Ciudad Real, la identidad del llamado Bronce de La Mancha parece bastante clara en lo que se refiere tanto a los sistemas de poblamiento como a los objetos relacionados con los poblados, si bien los modos exactos de asentarse las gentes que habitan tan dilatado espacio varian de unas zonas a otras, en dependencia de los condicionamientos geográficos y económicos de cada lugar y aunque los registros arqueológicos registren diferencias, posiblemente de origen funcional. La información disponible es aun escasa, pero partir de la existente creemos que la imagen de una edad del Bronce homogénea en La Mancha es una conjetura bastante 
razonable, al margen de las variantes que sea necesario establecer por diferentes motivos.

Cuestión distinta es conocer el origen de este grupo cultural. Desgraciadamente la documentación que poseemos actualmente sobre época calcolítica en La Mancha es todavía muy escasa, pues se limita a la noticia de algunos yacimientos y a unos cuantos hallazgos aislados escasamente representativos e insuficientes para aproximarnos siquiera a una hipotética reconstrucción elemental de ese momento previo. Sin embargo tan parcas pruebas bastan para demostrar que La Mancha estaba poblada con anterioridad a la aparición de las sociedades de la edad del Bronce que habitan aldeas por lo general fortificadas o situadas sobre lugares de naturaleza apta para su defensa. No es necesario, en consecuencia, rastrear penetraciones desde el exterior a través de distintas vias de comunicación para explicar la aparición de tales aldeas, que bien pueden ser la razonable continuación del poblamiento anterior, posiblemente de carácter más disperso y menor permanencia en sus asentamientos, factores ambos que contribuyen a aumentar las dificultades para la localización de sus cabañas. Ello no supone rechazar la posibilidad de contactos a través de espacios intermedios y áreas limítrofes, y no solo por supuesto en el caso del sureste de Albacete, pero si cuestiona la teoria de la llegada de gentes desde el exterior - argáricas, valencianas, cuando no trasmediterráneas...- como única explicación para la aparición de las primeras concentraciones de población que hoy por hoy conocemos en La Mancha (Nájera, 1984).

Interpretaciones mantenidas por ciertos autores, partidarias de explicar el Bronce manchego (al margen de que se acepte o deseche su posible unidad cultural) como consecuencia de la llegada de pueblos o de influencias exteriores, se han apoyado por lo general en la identificación de algunas similitudes tanto en lo que se refiere a los tipos de poblado como a los materiales arqueológicos, sobre todo cerámicos y metálicos, recuperados en las excavaciones. Aplicando ese método comparativo hay quien propone ver el poblamiento de la edad del Bronce en La Mancha como un reflejo de la cultura argárica, si no consecuencia directa de su expansión, de los poblados fortificados valencianos e incluso en relación con talaiots y nuraghes. Un método de trabajo de ese tipo necesariamente crea dificultades, al margen de los errores que eventualmente pueda contener, pues las comparaciones se establecen por lo general a partir de unos cuantos elementos aislados previamente seleccionados, elementos que, en efecto, presentan similitudes formales indudables, aunque para ello se desprecien las evidentes diferencias, al no basar la aplicación de los paralelismos en la confrontación de conjuntos 


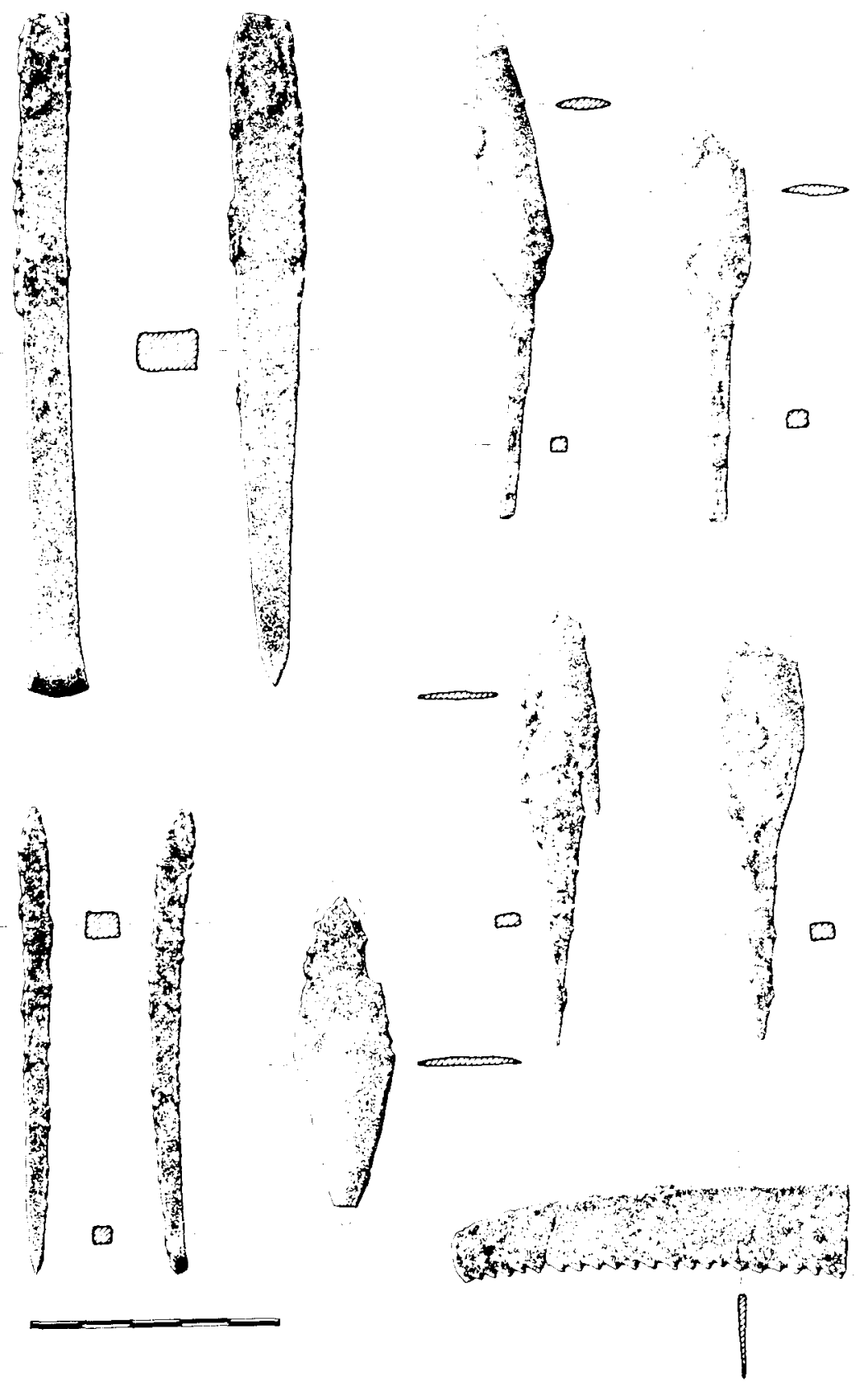

El Acequión (Albacete): Objetos metálicos 
completos y representativos, haciéndola por el contrario a través de objetos individuales, unas veces de carácter extraordinario en su propio contexto de procedencia y otras de concepción tan simple que resulta difícil aceptar que su repetición precise sustentarse en contactos y no sea consecuencia de una mera convergencia formal. Hasta qué punto paralelismos mal empleados pueden conducir a errores que luego perduran durante años, se comprueba releyendo, por ejemplo, la primera visión de síntesis de Sánchez Jiménez $(1947,1948)$ sobre lo que él llamaba «la cultura del Argar en la provincia de Albacete». La edad del Bronce local, conforme lo hemos recogido en otro lugar (Fernández-Miranda, Fernández-Posse y Martín, en prensa) aparece descrita como una manifestación más de la cultura argárica llegada desde su área nuclear gracias a una serie de mecanismos de difusión, pero empobrecida y marginal, degenerada precisamente a causa de la lejanía respecto de su lugar de procedencia.

¿Qué rasgos caracterizan a la edad del Bronce en La Mancha? Pese al escaso número de yacimientos todavía excavados con método adecuado, resulta a nuestro juicio posible promover ya algunas ideas al respecto. Parece, por ejemplo, claro que en la mayoria de los casos, según senalábamos más atrás, las gentes de esa época en La Mancha vivieron en lugares fácilmente defendibles y con frecuencia amurallados. Las recientes prospecciones, todavía en curso, en determinadas áreas de la provincia de Albacete confirman ese tipo de asentamiento protegido natural 0 artificialmente, al igual que ocurre en Ciudad Real, Toledo o sur de Cuenca, si bien se han detectado asimismo algunos pequeños asentamientos en apariencia abiertos, tal vez erigidos para desarrollar actividades esporádicas concretas y seguramente en dependencia siempre de unidades mayores.

La cambiante tipologia de esos asentamientos manchegos ha servido, en ocasiones, para plantear hipótesis sobre la sincronía o la sucesión en el tiempo de diferentes grupos identificados precisamente a partir de la variabilidad formal de sus poblados. En un reciente artículo, Martinez Navarrete (1988) llama la atención sobre tal cuestión, achacando esa supuesta diversidad cultural insinuada por algunos investigadores a una "escasa valoración de los aspectos funcionales». En efecto, y de acuerdo con esa autora, la visión en conjunto de todos esos yacimientos facilita «elementos de juicio suficientes para superar la idea de que los distintos tipos de asentamientos identificados puedan formar parte de una misma área cultural». Morras, motillas, castillejos, poblados en altura o en el llano, en tierras de secano, junto a cursos fluviales o en espacios palustres no son seguramente otra cosa que la expresión de diferentes pro- 


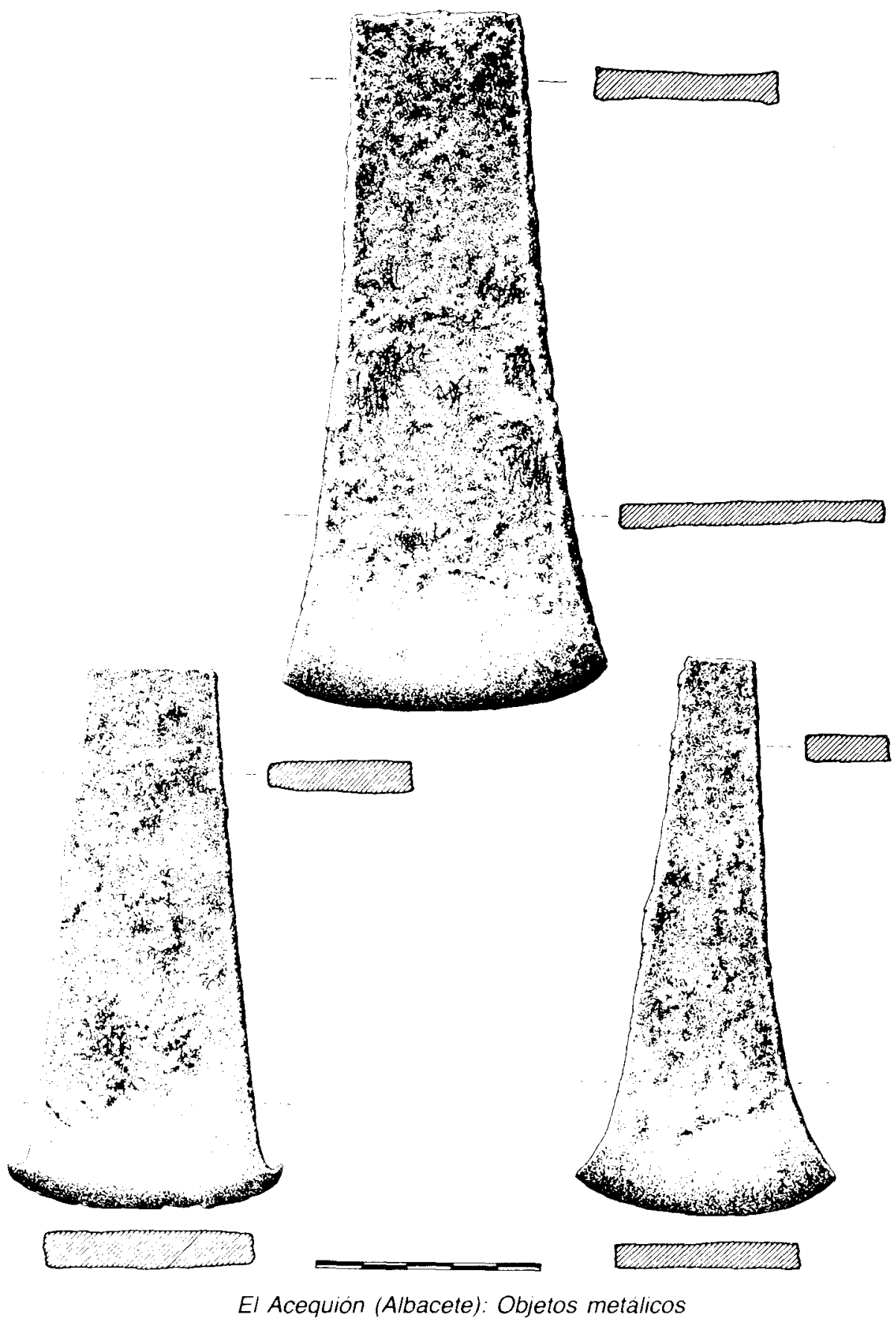


cesos de adaptación a un medio físico muy cambiante, como es el de La Mancha, por parte de distintos grupos sociales que posiblemente constituyen un área cultural común.

El análisis de los objetos materiales que identifican esa posible unidad cultural del Bronce manchego resulta significativo. Puede, evidentemente, encontrarse rasgos diferenciadores a partir de producciones singulares, e incluso cabe aceptar que algunos elementos, en determinadas circunstancias, lleguen a adquirir valor de indicadores cronológicos, como es, por ejemplo, el caso de la cerámica campaniforme, pero estimados en conjunto los objetos que caracterizan el registro arqueológico de los yacimientos excavados presentan una evidente analogía, así como una clara diferenciación frente a los que definen a otras unidades culturales, como puede ser El Argar. En consecuencia ni los poblados presentan más similitud con los de otras áreas geográficas que ser tales $y$ asentarse en lugares protegibles en algunos casos - la organización interior del espacio es diferente, su estructura distinta... - ni los ajuares son los mismos, al margen de que se repitan ciertas formas singulares. Todo lo cual en absoluto quiere decir que no puedan existir préstamos culturales, intercambios o contactos: la aparición de objetos realizados en marfil de muy posible origen africano, por ejemplo y en buen número en el poblado de El Acequión, término municipal de Albacete, constituye prueba irrefutable de la existencia de alguna clase de relación de intercambio, además de poner, de paso, en tela de juicio ciertas consideraciones habituales a propósito de la conexión entre presencia de materiales de origen exótico y relevancia de los sitios arqueológicos.

Un elemento que tal vez pueda contribuir a la definición de la edad del Bronce en La Mancha es la metalurgia, actividad a la que hasta ahora se ha prestado escasa atención, quizá debido al bajo número de objetos conocidos con anterioridad a las excavaciones recientes. En las formulaciones tradicionales de signo difusionista la supuesta escasez de objetos metálicos fue considerada sintomática (Sánchez Jiménez, 1947) —un rasgo más en consonancia con los restantes- del escaso relieve de este grupo cultural y su marginalidad. Tal argumento no constituyó, sin embargo, obstáculo para que se hablara de "cultura argárica" y de "edad del bronce", pese a las evidencias que se tenian de que el número de objetos metálicos era reducido y su tipología mucho menos variada, y por tanto distinta en conjunto, que la documentada en los poblados argáricos almerienses o murcianos considerados prototípicos.

En las excavaciones que desde hace algunos años estamos realizando en el yacimiento de El Acequión hemos logrado recuperar un conjunto de piezas metálicas que, a juzgar por las conocidas de otros 


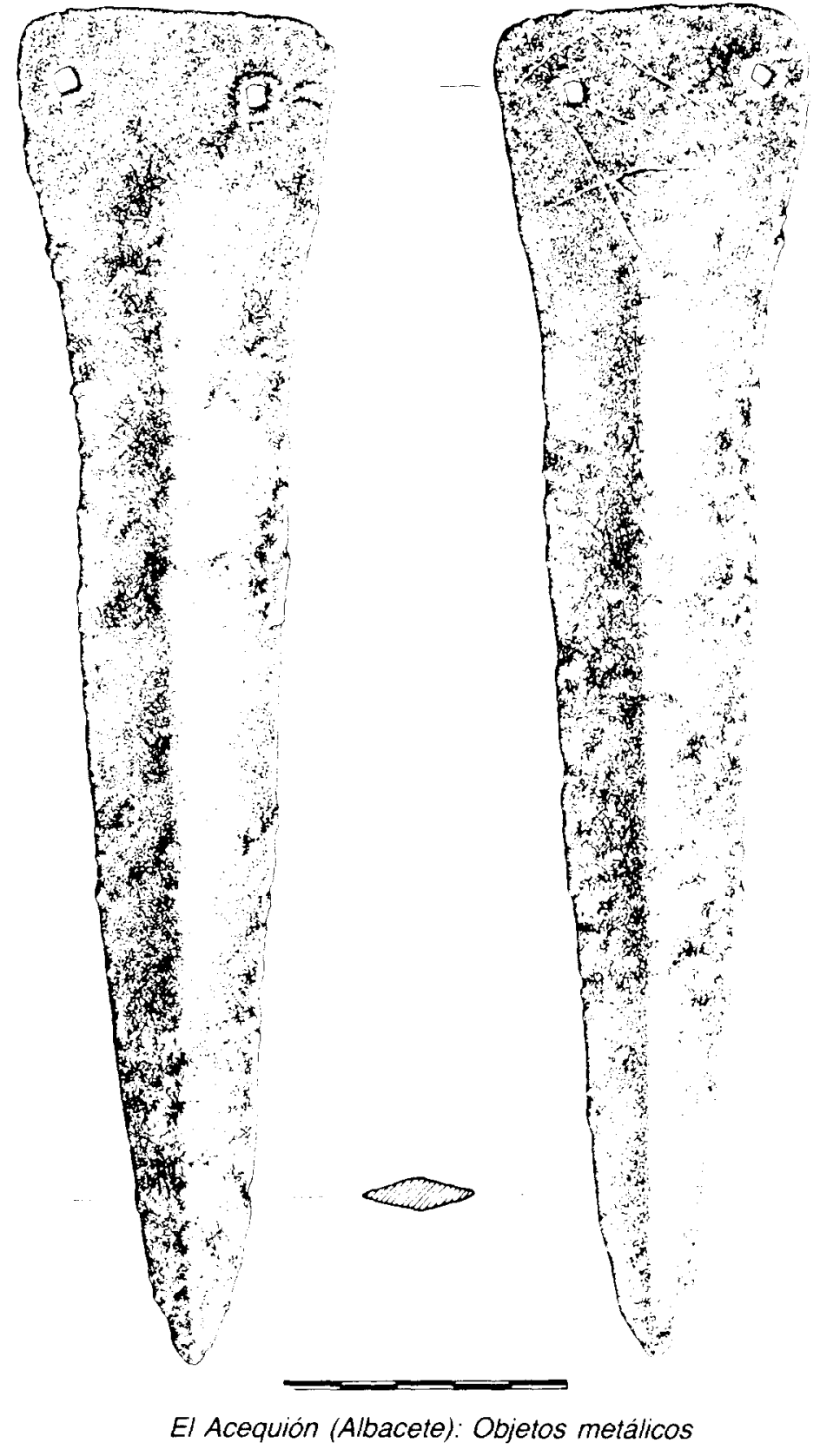


yacimientos, tal vez pueda estimarse desde un punto de vista formal bastante representativo de la metalurgía de la edad del Bronce en La Mancha: hachas planas, escoplos, puñales de lengüeta, una hoja de punal con nervio central, puntas de flecha tipo Palmela y de aletas, un fragmento de sierra y punzones de distintos tamaños. Las piezas están aun pendientes de su estudio definitivo, pero los primeros análisis efectuados nos permiten adelantar que se trata de cobres con una media de 96,9 por 100 de ese metal asociado a otros elementos escasamente representados, entre los que tan solo destaca el arsénico, con 1,81 por 100 del valor medio.

Las piezas metálicas de El Acequión son bastante similares en su composición, a excepción precisamente de sus contenidos en arsénico. Algunas son cobres casi puros, con valores por encima del 99 por 100 y en bastantes casos superiores al 98 por 100. Ninguna contiene estaño en cantidad significativa y tampoco aparecen otros elementos con relevancia. Cinco piezas contienen arsénico con valores próximos al 4 por 100 , otras tres superan el 2 por 100 y las restantes se sitúan por debajo, con frecuencia menos del 1 por 100. Puede afirmarse, por lo tanto, que de acuerdo con los resultados hasta ahora obtenidos, no existen indicios razonables para pensar que las gentes de El Acequión conocieran la aleación $\mathrm{Cu} / \mathrm{Sn}$. Parecen metalúrgicos de cobre, aunque tampoco pueda descartarse el añadido intencional de arsénico en ciertos casos, deducible no sólo de su presencia en algunas piezas con valores relativamente altos sino por el hecho de que en el curso de las excavaciones se hayan encontrado fragmentos de minerales que contienen tal elemento.

La comparación de estos análisis con los resultados obtenidos en series procedentes de otros poblados de la edad del Bronce en La Mancha permiten suponer que ese tipo de metalurgia debió constituir la tónica normal ${ }^{1}$. En efecto, la media de contenido en $\mathrm{Cu}$ de los distintos objetos analizados, con diferente tipología y en consecuencia teórica función, arroja valores incluso superiores a los de El Acequión, por encima del 97 por 100 excepto en Santa María del Retamar, que se fija en 96,9 por 100: La Encantada, 97,9 por 100; Morra de Quintanar, 97,8 por 100; Cerro del Cuco, 97,7 por 100 ... Es muy posible, en consecuencia, que el llamado "bronce» de La Mancha fundiera sus productos habitualmente en cobre, además de desconocer las aleaciones $\mathrm{Cu} / \mathrm{Sn}$, y que sus ma-

1 Queremos agradecer a José Sánchez Meseguer, a Katia Galán y a Helena Romero la autorización para hacer uso de los resultados de los análisis de los elementos metálicos de los yacimientos: Cerro de La Encantada (Granátula de Calatrava, Ciudad Real), Motilla de Sta. Maria del Retamar (Argamasilla de Alba, Ciudad Real) y Cerro del Cuco (Cuenca). 
nufacturas tan sólo experimenten variantes significativas, según los yacimientos que se estimen, por el contenido en $\mathrm{As}$ o $\mathrm{Pb}$, seguramente provocadas por la presencia de esos minerales formando parte del metalotecto de cobre utilizado, o en alguna ocasión fruto de una aleación intencional sustitutiva de $\mathrm{Sn}$.

¿Puede interpretarse el desconocimiento de la aleación Cu/Sn como índice de un bajo desarrollo tecnológico o como prueba de un escaso interés en obtener piezas metálicas de tales características? ¿Se debe exclusivamente a un problema de carencia de materias primas en la región y a la incapacidad para regular sistemas alternativos de aprovisionamiento? ¿Tiene todo ello, y cualquiera que sea la explicación técnica, un especial significado desde el punto de vista cultural?

Empecemos por esta última cuestión. Se conocen en este momento un centenar de resultados sobre composiciones metálicas en objetos procedentes de una docena de yacimientos y tan sólo un puñal triangular de doble remache y pequeño tamaño aparecido en el yacimiento de Los Cabezos A, término municipal de Almansa (Albacete) (Simón, 1988) presenta un contenido en estaño, 10,69 por 100, que sin duda corresponde a una aleación intencional para conseguir bronce. Dos piezas procedentes de La Encantada contienen asimismo estaño en abundancia, pero una parece un fragmento de fíbula de cronología muy posterior a la general del yacimiento y otro es un pedazo de metal de imposible clasificación y datación desconocida. Igual ocurre con la punta de Arrocinejos, término municipal de Chinchilla, un yacimiento de filiación imprecisa donde se produjo su hallazgo de forma casual y fuera de todo contexto arqueológico. En todos los demás casos los análisis reflejan fundiciones basadas en cobre, en ocasiones, como ya se ha indicado, con presencia relevante de arsénico, con trabajo habitual cie forja en caliente y a veces también en frio para avivar filos o retocar talones en el caso de alguna hacha, y rematar extremos de aletas o pedúnculos en puntas de flecha.

Valorar el significado que la metalurgía puede tener en el análisis conjunto del proceso cultural no es tarea sencilla, pese a ser asunto sobre el que existe amplia bibliografía y no poca discusión, tanto en sus planteamientos teóricos como en los meramente tecnológicos. Implica supuestamente un progreso técnico, aunque quizá no en sus inicios. Dicho de otra forma, puede admitirse que una metalurgia inicial destinada a la obtención de cobre haya sido algo relativamente fácil de conseguir si se cuenta con alguno de los minerales que lo proporcionan. La temperatura exigible no es necesariamente superior a la utilizada para cocer cerámica y la localización de los minerales puede ser hasta fruto de la casualidad. Sin embargo lograr una aleación $\mathrm{Cu} / \mathrm{Sn}$ requiere experimentar con mine- 
rales diferentes que deben asociarse en proporciones concretas: el conocimiento técnico es sin duda superior, posiblemente consecuencia de una larga manipulación previa y poco probable por azar, pues los contenidos de $\mathrm{Sn}$ en metalotectos de cobre, cuando aparecen, son por lo general muy bajos. Algo similar ocurre en el caso de aleaciones $\mathrm{Cu} / \mathrm{As}$, pero la dificultad para detectar su intencionalidad es mayor pues los metalotectos de cobre contienen con frecuencia As, incluso en cantidades elevadas.

En el caso que nos ocupa, resulta evidente la práctica ausencia de piezas hechas en bronce por aleación $\mathrm{Cu} / \mathrm{Sn}$, así como la presencia en contados casos de aleaciones Cu/As que podamos en principio considerar intencionales. La explicación al caso general puede descansar en el desconocimiento de las oportunas técnicas para su obtención, o deberse a la carencia de materia prima. Sobre la primera cuestión resulta imposible pronunciarse con la documentación existente, pues apenas conocemos restos de fundición u otros indicios relacionados con el tratamiento de minerales. Dada la considerable superficie excavada ya en algunos yacimientos y los leves indicios de actividad metalúrgica detectados podría suponerse que no debió ser tarea habitual. Pero, naturalmente, ello no deja de ser una mera conjetura por el momento, pues ningún poblado ha sido excavado en su totalidad y además una labor como la de fundir minerales, dada su potencial toxicidad, pudo perfectamente localizarse en un lugar separado del propio poblado. Si se confirma, como parece probable, el desconocimiento o la escasísima aplicación de técnicas para lograr aleaciones, tendríamos un elemento diferenciador de carácter tecnológico, pero quizá también económico, respecto del área argárica, en la medida en que las explicaciones posibles para tal "desconocimiento" pueden ser de indole diversa.

Un asunto de la mayor relevancia es sin duda las dificultades con que tropezarian estas gentes a la hora de proveerse de las materias primas necesarias para fundir sus objetos. La meseta, salvo en alguno de sus bordes montañosos, es espacio poco propicio para las mineralizaciones de cobre. En concreto en La Mancha oriental tan solo existen meros indicios en sitios aislados al este de Cuenca, hacia Landete, ya en plena serrania. Por lo que respecta a la provincia de Albacete se conocen algunos puntos también hacia la sierra, entre Alcaraz y Riopar, e incluso hay noticia de pequeños filones explotados hace años que bien pudieron proporcionar igualmente minerales de cobre en la antigüedad. El futuro estudio de esa zona, aun pendiente de realización dentro de nuestro proyecto de investigación, tal vez proporcione información más precisa, pero, en cualquier caso, no debe perderse de vista que se trata de mineralizaciones de escasa entidad y difícil detección, al no constituir 
áreas metalíferas de envergadura y fácil identificación visual, aunque no por ello debe descartarse su posible beneficio en tiempos prehistóricos. Si esa rareza se utiliza para explicar el aparente bajo número de piezas manufacturadas en cobre, aun más comprensible resultará aceptar que no existen aleaciones de estaño, pues este elemento brilla por su ausencia en la Meseta. Las mineralizaciones de estaño más próximas se sitúan hacia el sureste en la zona de Cartagena y por la Sierra de Los Pedroches hacia el suroeste, en ambos casos a más de $100 \mathrm{kms}$. de distancia en linea recta del área de la actual provincia de Albacete.

Una situación tan desventajosa sólo podría superarse importando los minerales $u$ obteniendo por comercio los productos manufacturados, opción esta última que parece, en principio, más atractiva dado el menor esfuerzo que implica para el transportista y supuestamente el mayor beneficio para la exportación y menor coste para quien importa. Sin embargo en el caso de La Mancha, y a tenor de los resultados que nos han proporcionado los análisis efectuados, no parece que se comerciara ni con minerales de estaño ni con piezas acabadas con tal metal incorporado. Podría ser prueba, por supuesto en ningún caso definitiva, en favor de la inexistencia de comercio con el área propiamente argárica para proveerse de piezas metálicas, pues la mayoría de las que se realizan allí están elaboradas en bronce con significativo contenido en estaño, aunque también existen casos de aleación Cu/As.

Otra opción será el comercio de la materia prima, es decir de los minerales. No sólo no existe evidencia alguna en favor de tal posibilidad sino que el desconocimiento del estaño más bien parece prueba de la inexistencia de relaciones exteriores a esos fines, lo que indirectamente apoyaría la hipótesis de una metalurgia local, quizá escasa al basarse exclusivamente en los reducidos recursos mineros más cercanos y básicamente a partir de cobre porque tan solo podria acceder a mineralizaciones de ese metal. La penuria de indicios de fundición en los poblados, sin ser significativa por el momento dados los pocos sitios excavados en extensión, encajaría perfectamente en esta hipótesis, pues podria deberse a una preferente localización del proceso metalúrgico en los mismos lugares en que se extrayeran los minerales, dadas las distancias que existen entre ellos y la mayoria de los poblados, transportándose luego los productos manufacturados, $\mathrm{o}$ al menos parcialmente tratados, $y$ no las materias primas minerales.

¿Todo cuanto antecede, significa que la metalurgia tuvo escaso interés para las gentes de la edad del Bronce en La Mancha? La relevancia de los productos metálicos puede analizarse, entre otras posibilidades, a partir de dos estimaciones básicas: que los objetos per- 
mitan utilidades con clara ventaja comparativa sobre herramientas de similar funcionalidad pero elaboradas a partir de distinta materia prima, o que en si mismos sean elementos de prestigio para quien los posee, sin descartar, claro está, la posible asociación de ambas estimaciones. La primera opción parece poco factible pues en el caso de que se hubiera producido tal vez debería haberse plasmado en la aparición de un mayor número de útiles metálicos e incluso llegar a provocar su importación. La segunda opción podría aceptarse al menos en algunos casos, por ejemplo los enterramientos en La Encantada, donde objetos metálicos forman parte de los ajuares funerarios (Nieto Gallo y Sánchez Messeguer, 1980), aunque tengamos dudas sobre si tal ritual debe considerarse extendido dentro de esta cultura. En todo caso el hecho de que los objetos metálicos aparecidos en esas sepulturas no se distingan de los que deparan los lugares de habitación confirma el carácter similar de esas manufacturas, y por tanto su posible fabricación local.

El hallazgo de objetos metálicos en tumbas obliga, por otra parte, a replantear el asunto de su supuesta rareza en el Bronce de la Mancha. La imagen que poseemos a propósito de la riqueza metalúrgica de muchos grupos culturales de la edad del Bronce peninsular se encuentra directamente determinada por el tipo de excavaciones que se hayan llevado a cabo en cada caso. Cuando se han excavado primordialmente poblados, el número de objetos metálicos suele ser bajo, y en ese sentido las piezas que ha proporcionado El Acequión, por ejemplo, no desmerecen en cantidad de las que suelen encontrarse en poblados argáricos de tamaño similar. Sin embargo cuando las excavaciones se encaminan preferentemente a exhumar tumbas, como ocurrió por ejemplo en el caso del propio Argar, el número de objetos metálicos aumenta espectacularmente, lo que equivale a proponer que el arqueólogo basa su percepción de la metalurgia de una cultura en piezas separadas de la circulación ordinaria, así como de su posible función utilitaria. En el caso de La Encantada resulta evidente, al menos de acuerdo con la información actualmente disponible para el yacimiento, la preferente localización de los hallazgos metálicos en ajuares funerarios, lo que podría, por un lado, apoyar la hipótesis de su valoración como objetos de prestigio apartados de la circulación, y por otro poner en entredicho, al menos parcialmente, la imagen del Bronce manchego pobre en esa clase de objetos, un extremo este que, aunque con otra interpretación dada la posición de los hallazgos, tampoco puede formularse a partir de lo observado hasta ahora en El Acequión. En todo caso, y cualquiera que sea la explicación funcional, lo que parece bastante comprobado es el carácter local de esta metalurgía, tanto por la tecnología básica que parece detectarse como por la tipología de los útiles registrados. 
Sin embargo existen a la vez evidencias de relaciones exteriores, la más clara sin duda la que se deduce de la presencia de objetos de marfil, con hallazgos como los de El Acequión, donde en algunos casos aparecen incluso piezas a medio fabricar, lo que permite suponer que se importaba la materia prima para su posterior elaboración local de acuerdo con los gustos y necesidades locales. La relativa complejidad formal de algún producto metálico, como puede ser el puñal alabarda de ese mismo sitio, podría considerarse igualmente prueba en favor de ciertas influencias exteriores, al menos en lo que atañe a la moda o tipo de los útiles; y lo mismo se podría pensar de la aparición de puntas de flecha tipo Palmela. Si los contactos exteriores son evidentes y, pese a ello, no se documentan útiles manufacturados en bronce $\mathrm{Cu} / \mathrm{Sn}$, solo cabe pensar que o bien la ventaja comparativa que su utilización comportaría - sea de corte funcional o derivada del prestigio emanado del objeto- resultaba mínima, o bien que los costes de un comercio de esa clase de piezas eran excesivamente elevados en relación con las ventajas que su posesión podía suponer. En esta tesitura, unida a la escasez de recursos minerales en la región, podría entenderse que la metalurgía de la edad del Bronce en La Mancha no fuera abundante, que estuviera realizada habitualmente en cobre o que se viera costreñida frecuentemente a producir objetos de prestigio o exclusivamente con valor de piezas de intercambio. No seria un caso aislado, pues por ejemplo en el Bronce valenciano da la sensación que se reproducen situaciones muy parecidas, al menos en algunas de sus áreas geográficas. Una metalurgia, en suma, de carácter local y autoabastecimiento, dirigida a obtener unos objetos que probablemente no representaron nunca un elemento cultural relevante desde el punto de vista tecnológico y tal vez algo más desde la perspectiva de las posibles ventajas que pudieran derivarse de su posesión en la esfera del prestigio social. 


\section{BIBLIOGRAFIA}

Bosch-Gimpera, P., 1954: "La Edad del bronce de la Península Ibérica». Arch. Esp. Arq., págs. 45-92, Madrid.

Colmenarejo, R.; Galan, C.; Martínez Peñarroya, J., y Sánchez MeSEGUER, J., 1987: «La Motilla de Santa María del Retamar (Argamasilla de Alba, Ciudad Real.)" Oretum III; 80-108.

LULL, V., 1983: La "Cultura" de El Argar. Madrid.

Martínez Navarrete, $M{ }^{a}{ }^{a}$ I., 1988: “Morras, Motillas y Castillejos: ¿Unidad o pluralidad cultural durante la Edad del Bronce de La Mancha?". Homenaje a Samuel de los Santos, Albacete, 81-92.

NAJERA, T., 1984: La Edad del bronce en La Mancha Occidental. Resumen de Tesis Doctoral. Universidad de Granada.

Nieto Gallo, G. y Sanchez Meseguer, J., 1980: El Cerro de La Encantada (Granátula de Calatrava. Ciudad Real. E.A.E. 113, Madrid.

Romero, H. y SÁnchez Meseguer, J., 1988: "El Cerro del Cuco o de la Coronilla. Una yacimiento del área suroriental de la Mancha", I Congreso Historia de Castilla-La Mancha, tomo II, 335-342.

SANCHEZ JIMÉnEZ, J., 1974: "La cultura de El Argar en la provincia de Albacete", III C.A.S.E., Murcia, 73 y ss.

SÁNCHEZ JIMÉNEZ, J., 1948: "La cultura argárica en la provincia de Albacete. Notas para su estudio", Actas y Memorias de la Sociedad Española de Antropología, Etnología y Prehistoria, 96 y ss.

SIMÓN, J. L.: La Edad del Bronce de Almansa. Albacete, 1987.

TARRADell, M., 1946: "Sobre la delimitación geográfica de la cultura de El Argar», / C.A.S.E., Albacete, 139-145.

- 1949: "La Península Ibérica en la época de El Argar", V C.A.S.E. y I.C.N.A., Almeria, 72-85.

- 1965: «El problema de las diversas áreas culturales e la Península Ibérica en la Edad del Bronce". Miscelanea en Homenaje al Abate Breuil, t. II, Barcelona, 423-430. 